\title{
The Social, Anti-Social Network: A Qualitative Study on Pro Social Benefits of Online Multiplayer Gaming
}

\author{
Kent L. Hastings
}

Follow this and additional works at: https://researchrepository.wvu.edu/etd

\section{Recommended Citation}

Hastings, Kent L., "The Social, Anti-Social Network: A Qualitative Study on Pro Social Benefits of Online Multiplayer Gaming" (2015). Graduate Theses, Dissertations, and Problem Reports. 5781.

https://researchrepository.wvu.edu/etd/5781

This Thesis is protected by copyright and/or related rights. It has been brought to you by the The Research Repository @ WVU with permission from the rights-holder(s). You are free to use this Thesis in any way that is permitted by the copyright and related rights legislation that applies to your use. For other uses you must obtain permission from the rights-holder(s) directly, unless additional rights are indicated by a Creative Commons license in the record and/ or on the work itself. This Thesis has been accepted for inclusion in WVU Graduate Theses, Dissertations, and Problem Reports collection by an authorized administrator of The Research Repository @ WVU. For more information, please contact researchrepository@mail.wvu.edu. 


\title{
The Social, Anti-Social Network: A Qualitative Study on Pro Social Benefits of Online Multiplayer Gaming
}

\author{
Kent L. Hastings \\ Thesis submitted \\ to Eberly College of Arts and Sciences \\ at West Virginia University \\ in partial fulfillment of the requirements for the degree of \\ Master of Arts in \\ Sociology \\ Joshua Woods, Ph.D., Chair \\ Jason Manning, Ph.D. \\ Jesse Wozniak, Ph.D. \\ Department of Sociology and Anthropology
}

Morgantown, West Virginia

2015

Keywords: video games, multiplayer, online gaming, qualitative Copyright 2015 Kent Hastings 


\section{ABSTRACT \\ The Social, Anti-Social Network: A Qualitative Study on Pro Social Benefits of Online Multiplayer Gaming}

Kent Hastings

Using the social capital and uses and gratifications perspectives, this study employs a qualitative, interview-based approach to studying the pro-social benefits of online multiplayer gaming. Through in-depth interviews, this study contributes to the literature of pro-social benefits of online multiplayer gaming by corroborating past research with evidence that online multiplayer gaming fosters the generation of social capital, both bridging and bonding, and cultural capital. Further, online gaming offers players a sense of community, provides them the tools to form and work together in coordinated teams, and allows them to feel a sense of mastery, excitement, and accomplishment with each in-game victory. 


\section{TABLE OF CONTENTS}

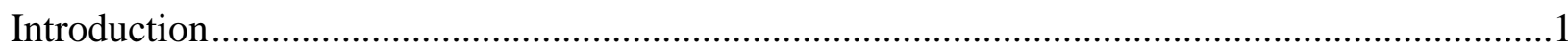

Literature Review

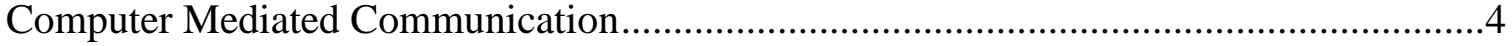

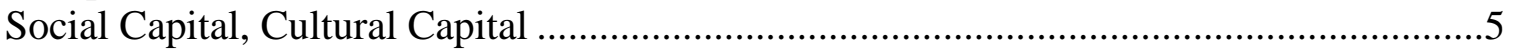

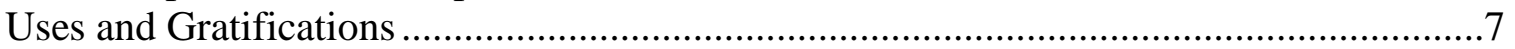

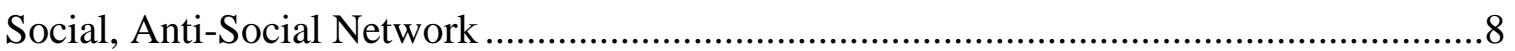

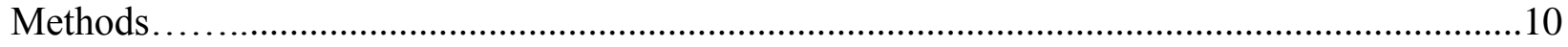

Results

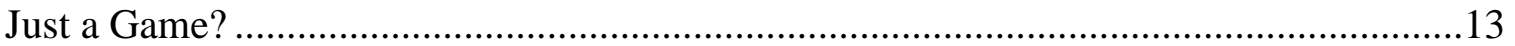

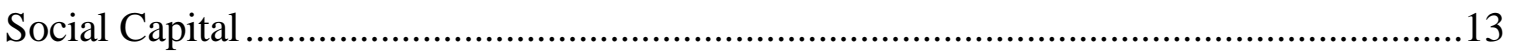

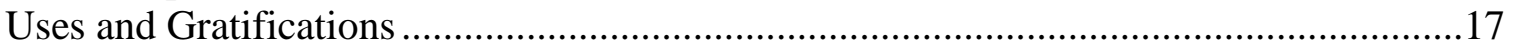

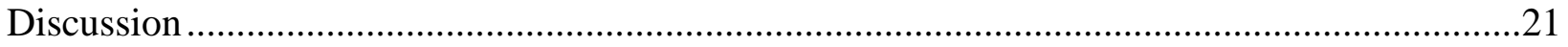

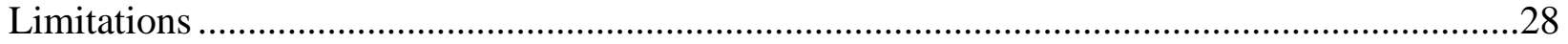


Online multiplayer video games are an increasingly popular, modern phenomenon. The online gaming community surrounding both PC and console games is growing at breakneck speed (Alvarez 2009). In 2010, consumers spent roughly 25 billion dollars on games, hardware, and accessories (ESA 2011). The online multiplayer gaming industry in particular is projected to reach 29 billion dollars in 2016 (DFC Intelligence 2011). The Microsoft online gaming service, Xbox Live, reports 48 million members across 41 countries (Microsoft 2014). Likewise, last year, Sony reported 110 million Playstation Network accounts (PlayStationLifeStyle.net 2013). In addition to Xbox and Playstation subscribers, gaming on PC is equally, if not more, popular. In 2012, it was estimated that 20 million players subscribed to online PC games, 10 million of which played World of Warcraft (MMOdata.net 2012). These online networks support communication functionality and relationship-building tools, intended to give players pro-social interaction options amidst their fantastic conquests.

The recently released Destiny (Bungie 2014), a Massively Multiplayer Online FirstPerson Shooter (MMOFPS) game similar to World of Warcraft (Blizzard Entertainment 2005), allows thousands of players to form online communities (Hsu and Lu 2007), wherein they may interact, collaborate, and compete in fantasy, sci-fi scenarios. The game's design revolves around pro-social contact between players by allowing existing friendships to strengthen through fierce firefights on exotic, alien planets and for complete strangers to join forces to save the galaxy.

Destiny grossed 325 million dollars in its first five days of sales (Karmali 2014), and it is only one among popular games with pro-social game mechanics. It is estimated that video games are played in $67 \%$ of U.S. homes, with the average gamer playing a minimum of eight hours per week (ESA 2011). Massively Multiplayer Online (MMO) gamers play even longer, up to 20 hours per week (Yee 2006a, 2006b). Destiny alone has already logged well over 100 billion 
hours of play-time since its launch (O’Brien 2014). Despite the potential pro-social uses of online gaming, previous literature has largely focused on negative outcomes.

Although it is possible to enjoy video gaming in moderation, there are numerous negative consequences of playing video games for extended periods of time, including addictive behavior (Griffiths 2000, 2008; Griffiths, Davies, and Chappell 2004; Grusser, Thalemann, and Griffiths 2007; Hussain and Griffiths 2009; Ko, et al. 2005; Ng and Wiemer-Hastings 2005; Thalemann, Wolfing and Grusser 2007), antisocial tendencies (Anderson and Bushman, 2001; Browne and Hamilton-Giachritsis 2005), trouble sleeping (Choi et al. 2009; Dworak et al. 2007; Griffiths et al. 2004; Hellstrom et al. 2012; Ng and Wiemer-Hastings 2005; Sharif and Sargent 2006; Tarzawa and Okada 2001; Van den Buck 2004), anxiety (Holtz and Appel 2011), stress related to perceived mandatory social participation in game-play (Hsu and Lu 2004), possible increased aggression (Gentile and Stone 2005; Griffiths 2000; Grusser et al. 2007; Harman et al. 2005; Villani 1999; Kim et al. 2008), reduced self-control, increased narcissistic traits (Kim, et al. 2008), interpersonal problems (Kim et al. 2008; Whang and Chang 2004), depression and psychological disorders (Ceyhan and Ceyhan 2008; Shapira et al. 2000; Shapira et al. 2003; Sheperd and Edelmann 2005; Spada et al. 2008; Ybarra, Alexander, and Mitchell 2005; Young and Rogers 1998), loneliness (Amichai-Hamburger and Ben-Artzi, 2003; Caplan 2003; Morahan-Martin and Schumacher 2003; Stepanikova, Nie, and He 2010), self-esteem issues (Kim and Davis 2009; Niemz, Griffiths, and Banyard 2005), and inadequate social skills (Caplan 2005, 2007; Liu and Peng 2008, 2009; Lo, Wang, and Fang 2005).

Predating the above literature on negative outcomes of online gaming are numerous studies that attempted to connect the violence of video games with arrested social development and violent outbursts. These studies often overlooked potential pro-social benefits of online 
gaming, but this was likely because the studies were undertaken while online gaming was in its infancy and had not become as sophisticated as it is now (Dill and Dill 1998).

Given the general lack of research on the pro-social effects of online gaming and the increased sophistication of virtual interaction, a number of stakeholders, such as parents, the video games industry, and gamers themselves, would benefit from learning about the potential pro-social benefits from online gaming, especially their impact on social interactions (Nielson 2010). Although gaming has some potentially harmful consequences, mostly concerning excessive play, it can have a positive impact on players' lives. This study contributes to the literature of online gaming by focusing on the positive, pro-social aspects, such as relationship formation, development, and maintenance and personal well-being from teamwork and cooperative play of gaming, rather than the potential negative consequences. For example, Star Wars: Galaxies (Sony Online Entertainment 2003) allowed players to create relationships with one another within the Star Wars mythology through cooperative combat, something commonplace in online gaming, while also encouraging non-violent cooperation, where players could assume the roles of galactic trader, entertainer, or architectural engineer.

Through in-depth interviewing, this study seeks to understand the driving forces that may draw newcomers and veteran players alike into the world of online video gaming. What are the social functions of online multiplayer video games that keep the controllers in the hands of players across the world? This study finds that online multiplayer gaming is capable of generating both bridging and bonding social capital (Bourdieu 1982; Castiglione, Van Derth, and Guglielmo 2008; Putnam 2000) and cultural capital (Bourdieu 1982) for players. Further, online gaming offers players a sense of community, provides them the tools to form and work together 
in coordinated teams, and allows them to feel a sense of mastery, excitement, and accomplishment with each in-game victory.

\section{LITERATURE REVIEW}

Online multiplayer video games have been studied as a form of computer mediated communication (CMC), since online video games offer communication features such as voice and instant messaging (IM). Destiny (Bungie 2014), for example, allows players to communicate with other players from their online-friends-list using IM, voice messaging, or direct, real-time voice communication. Destiny also allows communication with strangers via in-game social interaction, which approximates real-life interaction by requiring both players to face one another in the game world and initiate interaction. Once interaction is achieved, players may converse using real-time voice communication and can join forces and work together. Strangers who meet initially in this manner are able to add one another to his online-friends-list so that future communications and team-ups are made easier. Many of these features are standard in online multiplayer games.

\section{Computer Mediated Communication}

Where face-to-face (FTF) communication affords people the ability to see one another while hearing their partners, using the many audible, visual, physical, and verbal cues to enrich the conversation with extra layers of meaning, CMC often does not permit this level of personal interaction (Daft and Lengel 1986; Kock 2005). In fact, users of CMC experience a certain level of anonymity (Morahan-Martin and Schumacher 2003). Past research has suggested that CMC is more often used by shy individuals because the anonymity of CMC allows individuals to “control social interactions" (Morahan-Martin and Schmacher 2003: 662). Further, CMC allows

a user to control precisely how he presents himself to the world, especially through word choice, 
since users do not have to respond in real-time and may take as much time as needed to construct the perfect message (Morahan-Martin and Schumacher 2000). Because CMC users may communicate from the relative privacy of their own homes, through the screens of their personal phones, or even across online-game networks, there may be less fear of being judged or a greater willingness to express their own personal opinions (Caplan 2005). CMC users have even described online social interaction as a "socially liberating experience" (Davis, Flett, and Besser 2002: 725).

It is possible, however, that with greater anonymity in social media communications, users may be more likely to falsely represent themselves to other users, since there are far fewer consequences for dishonesty in online communication and far fewer opportunities to be caught in a lie (Cornwell and Lungren 2001; Noonan 1998). On the other hand, users of CMC may have more freedom to explore their own personalities, generating mini-experiments wherein they test their self-presentations with other users to determine how exactly they can best represent themselves further online or even in FTF communication; they may use social media as "identity workshops," so to speak (Morahan-Martin and Schumacher 2000: 662; Turkle 1995). Further, McKenna, Green, and Gleason (2002) found that users who were better able to express their true selves online without fear of being judged or rejected formed meaningful relationships that were able to endure and even in some cases transfer to real-life, FTF friendships. Because of these reasons, for many, CMC is "more socially desirable" (Walther 1996: 17) and may be "relatively easier...less risky... and more exciting” (Wallace 1999: 182).

\section{Social Capital, Cultural Capital}

Social capital is an important concept within personal relationships. Understood as the level of connectivity a social actor has with others (Bourdieu 1982), social capital can be 
increased through building social connections, as social interaction can open up access to job opportunities or valuable information (Biggart 2002). Whereas social capital can be accumulated through relationship formation, cultural capital, or the ability to "embody the language, accents, and mannerisms of elites" (Biggart 2002: 278), cannot normally be gained so easily, since elites may reject pretenders who are not cut from the same cloth, regardless of how well they attempt to act the part.

Anheier, Gerhards, and Romo (1995) found support for Bourdieu's social topography theory, which states that social and cultural capital help determine the distribution of social actors in social space. If we consider online gaming a social space, a space where actors may enter by logging in and interact with one another in a number of ways, any one player's accumulated social and cultural capital could suggest his positioning in the online gaming world. Social and cultural capital are useful concepts in studying CMC relationships, just as they are in FTF relationships.

IM and other text-based communications, popular forms of $\mathrm{CMC}$, have been shown to increase an individual's social capital much in the same way that FTF communication does (Lin 2011). According to Lin (2011), the factors that influence the acquisition of social capital are "commitment, reciprocity, shared codes and language, shared narratives, centrality, and network ties" (p.105). These same factors are also present in online video games (Hsiao and Chiou 2012; Trepte, Reinecke, and Juechems 2012; Zhong 2001).

Social capital can be measured in terms of bridging social capital and bonding social capital (Castiglione, Van Derth, and Guglielmo 2008; Putnam 2000). Bridging social capital refers to social ties wherein individuals are informed and or inspired by one another, whereas bonding social capital refers to social ties wherein emotional support and deeper feelings of 
belonging are possible (Steinkuehler and Williams 2006; Williams et al. 2006). Research has shown that online games provide a good source of bridging social capital (Huvila, Holmberg, and Widen-Wulff, 2010; Steinkuehler and Williams 2006; Williams et al. 2006). However, bonding social capital was found primarily between players who had offline relationships and physical proximity (Trepte et al. 2012; Zhong 2011) or were involved in organized teams, such as clans or guilds (Skorik and Kwan 2011; Trepte et al. 2012). Ducheneaut et al. (2007) suggested that bonding social capital would be possible in online multiplayer games provided that a "wind down" period of socialization allowed players to build relationships rather than focus on in-game, progress-related goals (p.163).

\section{Uses and Gratifications}

The uses and gratifications (U\&G) approach focuses on what individuals gain from a behavior and has been applied to research on video games (Wu, Wang, and Tsai 2010). The U\&G perspective assumes that users actively choose media based on the extent that it fulfills their desires and that social and psychological differences between users affect levels of fulfillment and therefore, levels of motive in their pursuit (Katz, Blumler, and Gurevitch, 1974; Parsons 1951; Pornsakulvanich, Haridakis, and Rubin 2008; Weibull 1985). Past U\&G research has identified several motives or gratifications for video game play, including entertainment, achievement, social activity, immersion, and escape (Bartle 1996; Courtois et al. 2009; Gee 2005; Griffiths et al. 2004; Griffiths and Hunt 1995; Hartmann and Klimmt 2006; Hellstrom et al. 2012; Hussain and Griffiths 2009; Kim and Kim 2010; Ko et al. 2005; Koo 2009; Lin and Lin 2011; Ng and Weimer-Hastings 2005; Smahel et al. 2009; Song et al. 2004; Wu et al. 2010; Yee 2006a, 2006b). Further, researchers have linked increased confidence as a motive for online game play (Puri and Pugliese 2012), as well as player-developed emotional tethers toward in- 
game characters or player avatars (player-controlled characters that represent the player's interaction with the game world) (Wolvendale 2006). Chief among these is social activity, the one aspect that defines online multiplayer games and separates them from the rest of the field.

\section{Social, Anti-Social Network}

Although much academic research has been devoted to the anti-social aspects of gaming (Hand and Moore 2006), as a form of CMC, online multiplayer gaming provides numerous opportunities for players to socialize and form relationships. Massively Multiplayer Online Role Playing Games (MMORPGs) allow players to fill numerous roles, both violent and non-violent, within online communities (Billieux et al. 2013; Greitemeyer, Traut-Mattausch, and Osswald 2012; Hsiao and Chiou 2012; Park and Chung 2011; Snodgrass et al. 2011; Trepte et al. 2012; Whang and Chang 2004; Zhong 2011); these differ from games such as Destiny and other shooters, which mandate that the player fulfill soldier-like functions in order to participate. The game worlds in MMORPGs, more so than in other MMO-games, extensively support social player-relationships. Some players invest heavily enough in in-game relationships that they may even favor them over real-life relationships (Ng and Wiemer-Hastings 2005). Some researchers even suggest that, despite the risks involved with extended play-time, the social benefits of participating in a social game-world and community greatly contribute to the psychological health of players that may not have access to FTF relationships or real-life community or are simply shy (Liu and Peng 2008; Lo, Wang, and Fang 2005; Ng and Wiemer-Hastings 2005; Skoric and Kwan 2011; Smahel et al. 2009). Researchers have linked increased immersion, defined as the level of engagement within a game and the extent to which the player's real-life environment is temporarily ignored or forgotten (Jennet et al. 2008), to the social aspects of game-play (Ducheneaut, Yee, Nickell, and Moore 2006; Griffiths et al. 2003; Kolo and Baur 
2004). Players' level of immersion was found to increase when playing against a human adversary (Cairns et al. 2013).

Besides increasing immersion, collaborative game-play can lead to emotionally fulfilling and long-lasting relationships. Because of online games' intense focus on cooperative and teambased play, deeper emotional connections are able to form between players who are not only communicating, but also acting together, working together, and sharing heightened emotional circumstances, such as a difficult victory or a crushing defeat (Billieux et al. 2013; Cole and Griffiths 2007; Greitemeyer and Mugge 2013; Greitemeyer et al. 2012; Hsu, Wen, and Wu 2009; Iacono and Weisband 1997; Kowert and Oldmeadow 2013; Lin and Lin 2011; Snodgrass et al. 2011; Trepte et al. 2012; Williams 2006; Wu et al. 2010; Yee 2002; Zhong 2011). Putnam (1993, 2000) found that team participation and the accomplishment of collective goals can improve the social and psychological quality of team members' lives.

Although team coordination is often a requisite to complete more difficult missions, ingame communications are often emotional and life-related (Kowert and Oldmeadow 2013; Pena and Hancock 2006). Players that are interested in working with teams on a more committed basis join or form guilds. These groups are commonly called clans in FPS-games, such as Halo 4 (343 Industries 2012) and Call of Duty: Ghosts (Infinity Ward 2013), or Fire-teams in Destiny (Bungie 2014). Regardless of their label, guilds, clans, and or fire-teams are organized teams of players committed to working together in order to be more successful within their respective game-worlds, whether this means practicing together to fight more efficiently together in FPS games or utilizing the strengths and weaknesses of class-based roles to tackle difficult in-game challenges in MMORPGs (Ang, Zaphiris, and Mahmood 2007; Billieux et al. 2013; Taylor 2006; Zhong 2011). Playing as part of a committed team carries many social benefits, including social 
support and long-lasting relationships (Cole and Griffiths 2007; Ducheneaut et al. 2006;

Ducheneaut et al. 2007). Like with other forms of CMC, some online multiplayer game relationships extend beyond the virtual gaming-world (McKenna et al. 2002; Williams 2006).

This research contributes evidence against the outdated notion that social solidarity only exists in the flesh (Collins 2005). In an evolving, inter-connected world, CMC has proven to be a reliable alternative to FTF interaction. Both the social capital and $U \& G$ perspectives have proven themselves important in the study of CMC, and accordingly, both perspectives have informed the lines of questioning in this study. By discussing the bonds that develop between players in multiplayer video games, as well as the reasons that players turn to video games as part of their day-to-day activities, we gain a deeper, multi-faceted understanding of the functions that video games serve and the pull that draws players across the planet into the world of online multiplayer video games.

\section{METHODS}

This study was authorized on the $14^{\text {th }}$ of August, 2014 by the Institutional Review Board of West Virginia University. Fifteen semi-structured interviews were conducted via convenience and snowball sampling techniques. Respondents were promised confidentiality, and all names used in this work are fictitious. Interviewees were both undergraduate and graduate students at West Virginia University. A handful of interviewees were selected based upon the researcher's knowledge that they often played online multiplayer games. Other interviewees were verbally invited to participate in the study by the researcher as they waited for class to begin. Access to classrooms was available to the researcher due to his enrollment at West Virginia University and his Graduate Teaching Assistant status. Subsequent interviews were found via snowball sampling. Interviews, ranging from 30 minutes to one hour, were conducted in quiet locations on 
campus in order to minimize the inconvenience on student participants. Of the fifteen respondents, nine were men, and six were women. Ages ranged from 18 to 24 years old. All respondents were from the states West Virginia, Pennsylvania, and Maryland, with the exception of one respondent, who was from New York.

Care was taken to ensure that both men and women were able to participate and contribute to this study toward the gain of depth and complexity, but at the cost of pure random selection and any form of statistical analysis. This was done to approximate the industry demographics; 44\% of gamers are women (ESA 2013), whereas $40 \%$ of respondents in this study were women.

This study employs a methodological thick description approach (Geertz 1973, 1983). In order to achieve a deeper understanding of the role online multiplayer gaming has in players' lives, in-depth interviews allowed the respondents to directly communicate their thoughts in their own words. This allowed "large conclusions [to be drawn] from small, but very densely textured facts" (Geertz 1973 p.321). Although social functionality of online multiplayer gaming has been explored before, this study seeks to contribute to our present understanding by using a qualitative voice and addressing the newest games and innovations. Naturalistic and conversational interviews allowed the personal interpretations and experiences of the interviewees to surface (Frey, Botan, and Kreps 2000). This study was approached as a multi-case study (Small 2009). Using case-study logic (Yin 2002), each interview built upon the previous one until saturation was reached (Small 2009). Saturation was reached when the interview content began to become redundant.

Interviews began with the informant discussing his gaming preferences (console or PC, favorite games, etc.). The interview then progressed through fifteen questions intended to elicit 
information about social capital and the informant's uses and gratifications of online gaming. The interview format was highly flexible in the ordering of questions asked, however each interview contained the same or highly similar questions. The flexible, conversational approach to interviewing was aided by the researcher's general knowledge of online gaming. The fifteen recorded interviews were not transcribed verbatim. Instead, the interviews were transcribed and subsequently coded question by question, with any extraneous information or non-essential anecdotes passed over. This way, each interview could be compared with another easily, question by question, regardless of the unique flow of any one interview.

The interview protocol included the following topics: friends met while online gaming (social capital), offline friends who get together online (social capital), online friendships that have continued through FTF interaction (social capital), how online friendships differ from offline friendships (social capital), how online friendships are formed (social capital), online gaming roles (social capital, $U \& G$ ), the normal online gaming experience for the informant $(U \& G)$, and what features the informant looks for when selecting an online game to play (U\&G).

Snowball sampling proved an invaluable way of reaching out to potential interviewees. Although snowball sampling runs the risk of biasing the results, it is also a way of ensuring that all participants contribute meaningfully to the study (Small 2009). Since many of the interviewees directed the researcher toward those that they game with, a snowball sampling technique naturally led the study toward different types of gamers with different experiences and play styles. In most MMO-games, players are encouraged to vary their chosen character class with their teammate's choices, ensuring a variety of in-game skill sets to strategically conquer the game's challenges. In any given game, one character's weakness is another's strength, similar to a game of rock, paper, scissors; it is these abilities in concert that has proven to be the 
most effective way to play. So, any given gaming community will naturally tend to contain at least a few of each character or class, which logically would reflect the varied personalities of each player and alter his personal experiences (Park and Chung 2011).

\section{RESULTS}

\section{Just a Game?}

It is evident that video games grow to be more than just games. They take on a meaning that stretches far beyond winning and losing. Online games are virtual spaces where friends can get together to socialize as well as compete, a space where victories and failures alike can be enjoyed or commiserated, a space where relationships can be built or destroyed. Social capital is evident in online gaming as friendships are formed and players become more familiar with one another, they may offer tips for playing the game better, something Martin said was commonplace within clans and even more casual groups of players, or even advice for day-today life. This is an example of bridging social capital as defined by Putnam (2000). Bonding social capital was evident in the cases of Jack and Libby, who were able to develop strong, longlasting relationships through online play.

\section{Social Capital}

All of the respondents reported that they have some form of online relationship with those that they play with. In other words, none of the informants reported that they play online games solely with strangers. Interestingly, most of the informants reported generating some form of friendship with a complete stranger via online gaming. The following cases exhibit the acquisition of social capital, both bridging and bonding, and cultural capital. 
Libby, who often plays FPS games, such as Destiny, and RPG titles, such as the Diablo franchise online, actually met her boyfriend through online gaming. The pair met through cooperative game-play; the pair worked together to succeed in the game, each utilizing his or her unique character abilities and player strengths to overcome in-game obstacles and challenges. The cooperation necessary to succeed in the game eventually blossomed into an intimate relationship, and the couple elected to meet in-person. Here, the accumulation of the necessary social capital to communicate effectively within the game world coincided with bridging social capital, allowing the pair to develop a friendly foundation from which bonding social capital may develop. At the time of this writing, the couple, who lives some distance apart, plan both online and offline romantic dates. Their relationship endures both in-person and in-game. When the pair cannot get together face-to-face, they often schedule game dates. Bonding social capital was generated online, possibly because World of Warcraft allows players to interact with one another in-game in "social areas" where the players are not expected to perform game-progress-related functions, such as fighting enemies (Ducheneaut et al. 2007).

Linda also was able to generate bonding social capital and developed a relationship with a significant other via World of Warcraft, however her relationship was ultimately less successful. Linda had previously known the man from work, but grew closer through the use of online gaming. In fact, every one of the informants enjoyed the social aspect of online gaming. “Our group of friends really became closer by playing online together," Jack, a college senior, told me. Jack even made a friend from out of state over four or five years of playing together who eventually traveled in order "to party" with Jack and his friends. "You can definitely make friends online," Melissa told me. "I've actually met two different people [in real life] that I've met playing online." Melissa was part of a clan, an organized squad that plays together online, 
however now she has much less time to spend gaming. She maintained close relationships with those in her clan, a few of which she had not met in real-life prior. Another informant enjoyed using the online gaming experience to bond with her son. "I like the togetherness my son and I have when we're playing video games because we both get really involved."

Kirk used online multiplayer games instead of online chat-rooms, growing closer to his co-workers from a local restaurant over online competitions. "Games build on teamwork 'cause you're working together to win whatever game." He referenced online gaming as being congruous with alcohol in that both can be used as social lubricants. "You get closer and learn more about one another. It creates connections.”

Here, online bridging social capital allowed new relationships to strengthen between coworkers and germinated bonding social capital. Also, Kirk referenced how online social capital can be useful in FTF interactions. "It gave us something else to talk about." Stories of game-play achievements and especially in-game "water-cooler moments" generated conversation topics between Kirk and his new friends. Further, game-play among the co-workers eventually generated cultural capital as well. As the group played together, it became evident who the strong and weak players were. In other words, a hierarchy developed. The best players were attributed some status in gaming get-togethers. Status in this case was represented by picking teams or carefully organizing teams around the best players. This public team organization tends to emphasize who the best and worst players are.

Gerard spoke on cultural capital, specifically gaming status, within his group of friends. "You know who's good and who's not. You try to avoid players that you know are going to kill you." This avoidance could be interpreted as a display of respect. Nowhere was cultural capital 
more evident in online gaming than in clans. Martin, Melissa, and Linda spoke extensively on the subject of clans. The three agreed that clans have a hierarchy and have a leader who is dedicated enough to the game and to the clan that he will organize missions for players. Linda says, "Some people weren't really participating and he [the leader] was just like, 'look, if you aren't in, get out!" Martin said that players were able to move up through the ranks of a clan, but this was only possible through practice. "It boils down to game experience, how much time you put into it," he said. Higher ranks in clan membership come with greater responsibilities, including recruiting new players and ensuring high standards of play. "If you're doing something that people disagree with, nobody's going to follow you." Here, Martin is speaking of making bad in-game decisions, something that clan leaders simply cannot afford to do.

Stressfully high expectations are just one of the negative aspects related to cultural capital in online gaming. Shane enjoys playing with friends, however finds playing with strangers "annoying." "I've never met anyone that was just cool," he said. Here, he was referring to players who "yell at you for not playing 'right." This could be an example of cultural capital; elite players chastise other players who do not play according to their own norms.

Shane continues, "I have friends that play online, games like League of Legends, so I'm not worried about finding people to play with me. I don't feel like there's any point in making friends while playing video games. The whole online friend thing is just like- - I have friends that play online games, but they were already my friends [prior to playing]." Shane has never met someone online and befriended them. Shane, however, acknowledges that making online friendships is possible. 
Jack had shared many of Shane's negative experiences. He believes that the anonymity of playing online increases players' compulsions to talk, lowers inhibitions, and, "in a way, encourages anti-social behavior, like people go on rants over Xbox live." "Who is going to have a cussing rant in public, you know?" Nathan, a close friend of Jack's, said. Anonymity can also lead to lapses in sportsmanship between players. Melissa lamented, "I've had players tell me that I sound like a boy on the thing [microphone]... or call me names. 'You're a dyke! You're a lesbian!' So I think that's why I made the friends that I made and why we're so close today. They don't behave that way."

It becomes apparent that anonymity promotes the development of social capital between players, since without the visual and sometimes even audible clues of someone's appearance or personal background, the biases that a player may have for a certain group may never become agitated during an online game. However, it is also apparent that anonymity can also work against social capital, since players are able to vocalize their hate or distaste for certain groups without really owning these often embarrassing outbursts. At its worst, online gaming can become a platform for hate rhetoric and negativity, but at its best, the online gaming community can be a welcoming, pro-social group that learns to bond over a favorite past-time.

\section{Uses and Gratifications}

The following cases exhibit the various uses and gratifications that the informants experienced in their online game-play. One use that was common to all informants was using video games to engage with those close to them. Even those who play fast-paced online FPS games and enjoy fierce competition can also enjoy the social aspect of online gaming. They enjoy working together in the game and using the communication features, including voice chat, 
to talk as well as to play. Speaking of her gaming experiences, Melissa said, "I would chat with friends all day. I loved it." Gerard doesn't play often, but when he does play, he plays Titanfall. "I came home from work, and I know this sounds nerdy, but I played for 6 hours with my buddy. I took my Xbox [One] to his house and played online with him there." Shane perhaps said it best, "Video gaming is the medium that brings us together. That's like the vehicle between us, the video game."

Further, experiencing the rush of victory is an important draw to online multiplayer gaming as well as team membership and participation. "The feeling of outsmarting an opponent, there's nothing like it," Gerard, a casual gamer in his 20's commented. Here, Gerard is likely referring to the feeling of mastery gained through dominating an opponent. Similarly, Jack and Nathan both described the frenetic climax of a Titanfall game, where the winning side tries to wipe out the enemy forces as they attempt to retreat. "You don't really get anything for killing them. It's just fun. It's great when all your guys have the mechs [Titans], and everyone's surrounding the dropship [means of escape for losing players] and just blasting away." Perhaps symbolically, this is similar to how football players might celebrate together by embracing one another or through territorial displays of aggression after a touchdown or an interception.

Several informants likened playing online games to playing high school sports, although simulated conflict might seem like a far cry from real-life competition. These informants enjoyed working together as a unit or team. Real-life sports carry a momentum, an intrinsic tether to the heart that yanks it through the highs of victory while likewise dragging one through the lows of defeat. Is this what gamers are after, the thrill of overcoming or dominating an opponent? Melissa, primarily an FPS gamer, spoke of her participation in field hockey. "We were all in it together, and we all had to work out together and do all this painful running. We all cried and 
sweat and...blood and tears and everything. So, yeah. I love being a part of a team. Loved it.” She connected this with her experience playing Halo online with her friends. "Now that I think about it a little more... It's really competitive 'cause, you know, if you're slacking a little bit, people look at the kill/death ratio and see how many people you've killed in the game. And if I had less [fewer than her teammates], they'd be... mad and say 'Melissa, what are you doing? Step up!' So when I was super into it. It was really important that you got that kill. If that was the last kill for the game, and you died, they're going to be mad...I would have apologized for it [playing poorly]."

Chad, a former high school football player distanced video gaming and real-life sports. "The football team is highly organized. The quarterback gives the play, and you run what he says. It's [Video gaming] is a loose group of team. It's a loose group of people coming together." However, Chad agreed that losing or winning a video game can carry the same emotional weight as real-life sports. With regard to organization, Chad said, "When you play capture the flag [a popular online multiplayer mode in FPS games], you have a guy...constantly attacking... a guy constantly defending the flag...two other guys that were probably just creating mayhem. Those are your roles. That is your game-plan. That's what you came up with before you started playing. That sort of team concept, that sort of thing happens in real-life sports."

Martin echoed the sentiment that working together effectively is immensely rewarding in the FPS franchise, Call of Duty. "We go back to back so that we can protect one another from all angles." He described how he and his roommate travel through hostile areas together, each facing the opposite direction, increasing their fields of fire and likewise, their chances for survival. As he spoke, his eyes grew wide, and he raised his arms as if they were bringing a rifle 
to his shoulder. The excitement behind his words was palpable. It was evident that the rush of simulated gunplay drew Martin toward his "sticks" just as often as team spirit.

That teamwork and cooperation makes gaming more enjoyable was a point of view repeated throughout the interview process. However, not all players work together. According to Martin, "yeah, you can try to lone-wolf it [play as part of a team but not coordinate with other players], and you might get a few kill-streaks [multiple consecutive kills without dying] here and there, but you'll never be as successful." Here, Martin suggests that working together is essential to excel in the game.

All of the informants agreed that, although playing online multiplayer is a "great hangout," a "good stress reliever," and, "an escape from reality," they would prefer playing together, in-person, with their friends. The LAN (Local Area Network) party is the optimal experience for fans of online multiplayer with friends within convenient travel distance. "Playing at a LAN party is more satisfying because it feels important. Playing with friends gives it importance.” Nathan shares this sentiment with Jack, "It's a lot more fun. You can trash talkit's a different environment, but playing [with friends] is better in person. You [also] don't have to worry about connection issues or other technical issues of playing online.” During a Halo LAN party, players meet at one location (usually one of their homes) lugging TV's, Xbox consoles, controllers, and networking cords, split into teams and compete. "I'm always down for Halo parties," said Jason. This feeling of togetherness, however, can exist outside of close friends gaming together.

Doom (Id Software 1993), one of the first FPS games, was released in 1993 and inspired an online community that continues playing and modifying, or "modding", the game over 20 
years later. These modders collaborate through websites such as Doomworld.com (Doomworld 2003) to design new levels and update the game's visuals to take advantage of new technology that did not exist in the early 90's. This dedicated bunch keeps the game fresh, challenging, and through their work, enjoy a feeling of commitment and support with one another. All of the informants acknowledged that video games instill a sense of community with players, even if the informant did not participate in them. Nevertheless, the community aspect of video gaming was a popular draw for the majority of the informants. Games such as Destiny, World of Warcraft, League of Legends, and Call of Duty have community building tools, such as forums and clan competitions. Linda enjoyed the ability to connect with players around the world over a common interest, her love of Star Wars for example. Not all online communities are alike however; some are more cutthroat, while others are more tolerant of newcomers.

\section{DISCUSSION}

Both Shane and Martin described the process of getting a feel for the online community that plays a game, learning its mechanics, or how the game works (its controls, its rules, etc.), and how other players actually play the game. For example, Shane found the players of the MMORPG World of Warcraft to be more welcoming than players of the Halo or Call of Duty FPS franchises. He assumed that the social differences likely had to do with the increased competitiveness that shooters are more likely to attract. Martin explained that the M16 rifle in Call of Duty 4: Modern Warfare is the "most powerful weapon in the game" and, while the weapon is available initially to new players, veteran players often choose not to use it in order to encourage a more challenging battle. In fact, when veteran players elect to wield the M16 rifle, it forces all other players who are familiar with the game to follow suit, quickly turning the game into a long range shootout and discouraging any other tactic. Martin gave the name "cheezing" to 
describe purposely using the most powerful weapon in the game. "Cheezing" is met with vocal disapproval and even "booting" (voting to remove a certain player or group of players from the game).

It became clear that Shane and Martin were describing social and cultural capital respectively. In the world of online gaming, simply joining an online game could generate social capital, since the player would be in a position to communicate with other players, however this would not necessarily generate cultural capital. In order to gain cultural capital, the player must adopt the language of gamers, utilizing the slang that is often unique to each game. A player's ingame behaviors and mannerisms, which include how skillfully the player manipulates the controls and game environment can also generate cultural capital. By adopting the language, a new gamer can effectively communicate with other gamers, and by learning how to play skillfully, the player effectively plays alongside the "elites" or veteran players. This coincides with Lin (2011), who found that the acquisition of social and cultural capital is influenced by “commitment, reciprocity, shared codes and language, shared narratives, centrality, and network ties" (p.105).

Although Bourdieu suggests that cultural capital is primarily gained through inheritance (Biggart 2002), in the world of online gaming, players are able to generate or earn their own cultural capital through practice. Since many online games track player statistics, including the number of games played, victories won, losses, kills, deaths, accuracy, etc., and allow other players to view these statistics easily, players are always attached to their accomplishments or lack thereof. Cultural capital in this case can only meaningfully be gained, since a player cannot inherit a winning gaming career. 
There are instances where game developers play online with the player community and even have unique in-game avatars or other identifiers of their role in creating the game. It may be possible that in these instances, players may recognize these identifiers and respect the developer as being better at the game or at least as having intimate knowledge of the game, ask the developer for tips, or even follow the developer's example of play; any of these could be evidence of inherited cultural capital. It is possible that by using a certain avatar or other special identifier, a player may inherit some prestige, or cultural capital, but it is still more likely that cultural capital would be earned as a result of the developer's playing skill, rather than the simple recognition of having developed the game. Logically, the instance of a game developer who is skilled at computer coding but lacking in the quick reflexes necessary to excel could exist. His in-depth knowledge of how games work may earn him sales revenue from players, but it is likely that only his talent on the virtual battlefield will earn him the in-game respect, or cultural capital, of the player community.

In real-life, cultural capital can be imitated, and this imitation can be rejected because the interloper's background can be scrutinized. This type of scrutiny is highly unlikely and unnecessary in order to enjoy online gaming with strangers. The sole factor in players' ability to play with one another is, logically, the level of skill that they exhibit, since this is an observable trait of all players across all online games. Communication may or may not occur, but other players' skills will determine whether or not an enjoyable time is had playing. All other factors, such as race, age, sex, and socio-economic status can be concealed in an online game. For example, Anheiner et al. (1995) distinguish between the core and periphery, the mainstream and outliers, respectively. The elite players who have generated vast social and cultural capital through skilled play and relationships with other skilled players will logically occupy a different 
social space than players who are less skilled and or cheat. Although both types of players by random chance may be thrust into the same game instance, barriers to their inter-networking would likely exist. However, online gaming in general may present fewer barriers to friendship development than FTF interactions. Provided that a player make an effort to emulate correct/skilled play, even if he is new to the game, he will likely find other like-minded players in this core group with which to build friendships, regardless of his own gaming past (recent or career), his age, sex, or socio-economic status. As Bourdieu and Anheiner et al. (1995) point out, on the other hand, FTF interactions are often affected by social and cultural capital, which can be affected by outward appearances.

The particular form of communication used by gamers varies. Online games use two forms of communication for players: text and voice. Text is used more often to leave messages for players who are either offline or are in the middle of a game and cannot respond. Voice is used to communicate during games and within private user parties. Players may communicate about game strategy or hold personal conversations. A player might announce his intentions or an achievement, such as killing an enemy player, within the game world to his friends and or teammates without an expectation of a direct response. Players may also forgo voice communication with their teammates altogether. These players are what Jack and Martin call "lone-wolf" players. They see online multiplayer as more of a "free for all;" they operate toward the same goal as their team, however they do not actively communicate and or coordinate with their team members. This is not to say that online multiplayer ceases to be a social experience for these "lone wolf" players, however.

Nearly all games support an actual "free for all" game mode without teams, however "lone wolf" players still play in the team-based modes. Perhaps they enjoy participating in a 
team goal, even if it is simply to prove their ability to carry the team by posting impressive stats on the post-game report. They may enjoy the immersion of playing against human opponents (as opposed to the computer-controlled opponents in single-player games) (Ducheneaut et al. 2006; Griffiths et al. 2003; Kolo and Baur 2004), or they may just simply enjoy the game. The lone wolf player can be viewed as a counterfactual in this research, since he is playing a public, multiplayer game in an anti-social fashion.

The consensus among the informants was that, even though it can be fun from time to time to play as the lone wolf ${ }^{1}$, especially while waiting for friends to become available to play with, playing alone is extremely difficult. FPS games are generally balanced to favor team coordination, and while a good lone wolf player may take advantage of weak coordinated teamwork or cases where all players in the game are playing alone, any concerted effort against a lone wolf is highly likely to succeed. Teamwork and coordination are the keys to success in competitive online games.

While anonymity plays a role in encouraging anti-social behavior, it also promotes the development of new relationships. "You can tell anyone over social media anything about you without fear of them knowing who you are...I feel like that's a gateway to... friendship," Melissa said, reinforcing the concept of anonymous online communication as an "identity workshop" (Morahan-Martin and Schumacher 2000: 662). Despite the barriers to communication that CMC imposes (Daft and Lengel 1986; Kock 2005) as well as the often times chaotic online game environments, real relationships can still develop; Jack and Melissa both made plans to meet online friends in person, while Libby formed an intimate relationship through online

\footnotetext{
${ }^{1}$ Although informants admitted that they sometimes did play online multiplayer games as a lone-wolf player, none of the respondents described this style of play as being representative of their online multiplayer experiences. The lone-wolf player was not represented in the sample. This absence was not intentional on the part of the researcher.
} 
gaming. All informants also indicated that the anonymous nature of online multiplayer can also lead to especially anti-social interactions, often involving gratuitous swearing, bigotry, and poor sportsmanship.

This research validated past $U \& G$ research, which identified several motives or gratifications for video game play, including entertainment, achievement, social activity, immersion, and escape (Bartle 1996; Courtois et al. 2009; Gee 2005; Griffiths et al. 2004; Griffiths and Hunt 1995; Hartmann and Klimmt 2006; Hellstrom et al. 2012; Hussain and Griffiths 2009; Kim and Kim 2010; Ko et al. 2005; Koo 2009; Lin and Lin 2011; Ng and Weimer-Hastings 2005; Smahel et al. 2009; Song et al. 2004; Wu et al. 2010; Yee 2006a, 2006b). Online video games, especially team-based experiences, promote a sense of belonging and accomplishment to participants (Billieux et al. 2013; Cole and Griffiths 2007; Greitemeyer and Mugge 2013; Greitemeyer et al. 2012; Hsu, Wen, and Wu 2009; Iacono and Weisband 1997; Kowert and Oldmeadow 2013; Lin and Lin 2011; Snodgrass et al. 2011; Trepte et al. 2012; Williams 2006; Wu et al. 2010; Yee 2002; Zhong 2011). Although gamers often enjoy playing in-person if given the chance and opportunity (LAN parties require time commitments and the hassle of gathering all of the devices to play on a closed network rather than over the internet as well as require close proximity to friends who play video games), online multiplayer is an alternative to some, a necessity for others, or at least an immersive escape for the average gamer (ESA 2013). Gamers who have played sports in the past have come to recognize many of the same mechanics working within video games, including team leaders, specific roles, coordination, and shared end-goals.

In agreement with Putnam (2000), I offer the explanation that online multiplayer is highly sought after because it provides players a space for interaction and allows them to work together 
to achieve a goal. Working closely with other players provides for a sense of social emotion, or an emotional current that those working together are able to feel simultaneously. For example, we may observe an emotionally charged football team hugging and celebrating together at the end of a big play, just as we might observe a gamer leap from his chair in excitement after winning a match or shout at his TV in anger after a loss.

Further, many games offer incentives along with that end-goal of victory, such as increased abilities and or better in-game equipment or gear, which makes subsequent attempts slightly easier or opens up new avenues for team coordination and specialization. It is also likely that the online multiplayer component of a game prolongs the playability of any given game, and given the in-game rewards for multiplayer progression, enriches the overall experience a player has with a title. As games become more expensive, added value is likely a consideration for gamers shopping for a new title.

Further, online gaming provides players with a low-stress way of meeting new friends and maintaining relationships with current friends. Players use online gaming as a means of escape, just as Chad plays games primarily for the interactive story-telling aspects. His personal gratification lies in reducing the stress that he experiences in other aspects of his life and in sharing his gaming experiences with his friends. Players use games as vehicles to build new friendships or manage and strengthen existing ones; these players develop social and cultural capital through the unique channel of online multiplayer gaming. Still, other players play just to "waste time" as Martin says, but really, he is referring to spending time with his roommate, participating in an entertaining activity that both of them greatly enjoy. Those that play in clans desire to play competitively and enjoy being part of a working team, capable of conquering ever- 
increasing challenges. Online gaming is a flexible platform that allows players to have as much of a social or anti-social play experience as they desire, whenever they desire.

From the run-and-gun players of Doom and Call of Duty to the fantasy, exploration, and relationship-building players of World of Warcraft, Destiny, and Star Wars Galaxies, online gaming provides an ever-broadening, pro-social space for relationship development and personal gratification.

\section{LIMITATIONS}

This research is purely qualitative and due to its design is purely speculative in its interpretations of the informants' input. Given the small sample size, this study does not claim to hold a representative sample of online gamers or even of college-age gamers. Gender differences in social capital and the uses and gratifications of online multiplayer games did not surface in this research, although gaming demographics by game genre suggest that they might exist (ESA 2013). Although this research is speculative, it builds upon prior, established research, and all interpretations are grounded in a solid comprehension of online gaming as both a field of study and as a fond hobby. This research should be viewed as a small, multiple-case study of fifteen

online gamers that validates the assumptions and supports the conclusions of prior research into the pro-social benefits of online multiplayer gaming. 


\section{REFERENCES}

343 Industries. 2012. Halo 4. Video Game. Redmond, WA: Microsoft Studios.

Alvarez, M. 2009. Game Sites Growing 10-Times Faster than Internet. Comscore. Retrieved September 5, 2014 (http://www.atelier.net/en/trends/articles/comscore-game-sitesgrowing-10-times-faster-internet).

Amichai-Hamburger, Y. and E. Ben-Artzi. 2003. "Loneliness and Internet Use." Computers in Human Behavior 19: 71-80.

Anderson, C. A., and B. J. Bushman. 2001. "Effects of Violent Video Games on Aggressive Behavior, Aggressive Cognition, Aggressive Affect, Physiological Arousal, and Prosocial Behavior: A Meta-Analytic Review of the Scientific Literature. Psychological Science 12: 353-359.

Ang, C. S., P. Zaphiris, and S. Mahmood. 2007. "A Model of Cognitive Loads in Massively Multiplayer Online Role Playing Games." Interacting with Computers 19(2): 167-179.

Anheier, H. K., J. Gerhards, and F. P. Romo. 1995. "Forms of Social Structure in Cultural Fields: Examining Bourdieu's Social Topography." American Journal of Sociology 100(4): 859903.

Bartle, Richard. 1996. Hearts, clubs, diamonds, spades: Players who suit MUDS. Retrieved September 5, 2014 (http://mud.co.uk/richard/hcds.htm).

Blizzard Entertainment. 2005. World of Warcraft. Video Game. Irvine, CA: Blizzard Entertainment.

Biggart, N. W. ed. 2002. Economic Sociology. Malden, MA: Blackwell Publishers Inc.

Billieux, Joel, Martial Van der Linden, Sophia Achab, Yasser Khazaal, Laura Paraskevopoulos, Daniele Zullino, Gabriel Thorens. 2013. "Why Do You Play World of Warcraft? An InDepth Exploration of Self-Reported Motivations to Play Online and In-Game Behaviors in the Virtual World of Azeroth." Computers in Human Behavior 29: 103-109.

Bourdieu, Pierre. 1982. "Les Rites d'Institution," Actes de la Recherche en Sciences Sociales 43: 58-63.

Browne, K. D. and C. Hamilton-Giachritsis. 2005. "The Influence of Violent Media on Children and Adolescents: A Public-Health Approach.” The Lancet 365(9460): 702-710.

Bungie. 2014. Destiny. Video Game. Santa Monica, CA: Activision.

Cairns, Paul, Anna L. Cox, Matthew Day, Hayley Martin, and Thomas Perryman. 2013. "Who But Not Where: The Effect of Social Play on Immersion in Digital Games." Int. J. Human-Computer Studies 71: 1069-1077.

Caplan, S. E. 2003. "Preference for Online Social Interaction: A Theory of Problematic Internet Use and Psychosocial Well-Being." Communication Research 30: 625-648. 
Caplan, S. E. 2005. “A Social Skill Account of Problematic Internet Use.” Journal of Communication 55: 721-736.

Caplan, S. E. 2007. "Relations Among Loneliness, Social Anxiety, and Problematic Internet Use." CyberPsychology and Behavior 10: 234-242.

Castiglione, D., J. W. Van Derth, and W. Guglielmo. 2008. The Handbook of Social Capital. Oxford: Oxford University Press.

Ceyhan, A. A., and E. Ceyhan. 2008. "Loneliness, Depression, and Computer Self-Efficacy as Predictors of Problematic Internet Use." CyberPsychology and Behavior 11: 699-701.

Choi, K. H. Son, M. Park, J. Han, K. Kim, and B. Lee. 2009. "Internet Overuse and Excessive Daytime Sleepiness in Adolescents." Psychiatry and Clinical Neurosciences 63(4): 455462.

Cole, H. and M. D. Griffiths. 2007. "Social Interactions in Massively Multiplayer Online RolePlaying Games." CyberPsychology and Behavior 10(4): 575-583.

Collins, R. 2005. Interaction Ritual Chains. Princeton, NJ: Princeton University Press.

Cornwell, B. and Lungren, D. 2001. "Love on the Internet: Involvement and Misrepresentation in Romantic Relationships in Cyberspace vs. Realspace." Computers in Human Behavior 17: 197-211.

Courtois, C., P. Mechant, L. De Marez, and G. Verleye. 2009. "Gratifications and Seeding Behavior of Online Adolescents." Journal of Computer-Mediated Communication 15(1): 109-137.

Daft, R. L. and R. H. Lengel. 1986. “Organizational Information Requirements, Media Richness, and Structural Design.” Management Science 32(5): 554-571.

Davis, R., G. Flett, and A. Besser. 2002. "Validation of a New Scale for Measuring Problematic Internet Use: Implications for Pre-employment Screening." CyberPsychology and Behavior 5(4): 331-345.

DFC Intelligence. 2011. Online Game Market Forecasts 2011. Retrieved September 5, 2014 (http://www.dfcint.com/wp/?p=307).

Dill, K.E. and Dill, J. C. 1998. "Video Game Violence: A Review of the Empirical Literature." Aggression and Violent Behavior 3(4): 407-428.

Doomworld. 2003. "Ten Years of Doom.” Retrieved February 11, 2015 (http://www.doomworld.com/10years/).

Ducheneaut, N., N. Yee, E. Nickell, and R. Moore. 2006. “'Alone Together?' Exploring the Social Dynamics of Massively Multiplayer Online Games.” Paper presented at the CHI, Games and performances. Montreal, Quebec. Canada. 
Ducheneaut, N., N. Yee, E. Nickell, and R. Moore. 2007. "The Life and Death of Online Gaming Communities: A Look at Guilds in World of Warcraft." Paper presented at the CHI. San Jose, CA. USA.

Dworak, M., T. Schierl, T. Bruns, and H. K. Struder. 2007. "Impact of Singular Excessive Computer Game and Television Exposure on Sleep Patterns and Memory Performance of School-Aged Children." Pediatrics 120(5): 978-985.

Entertainment Software Association. 2011. Industry Facts. Retrieved September 5, 2014 (http://www.theesa.com/facts/).

Entertainment Software Association. 2013. "Essential Facts About the Computer and Video Game Industry.” Retrieved April 14, 2014 (http://www.theesa.com/facts/pdfs/esa_ef_2013.pdf).

Frey, L., C. Botan, and C. G. Kreps. 2000. Investigating Communication: An Introduction to Research Methods ( $2^{\text {nd }}$ Ed.). Boston: Allyn and Bacon.

Gee, J. P. 2005. "What Would a State of the Art Instructional Video Game Look Like?" Innovate 6. Retrieved September 5, 2014 (http://www.ics.uci.edu/ wscacchi/GameLab/Recommended\%20Readings/GeeInstructionalVideoGame-2005.pdf).

Geertz, C. 1973. The Interpretation of Cultures. New York: Basic Books.

Geertz, C. 1983. Local Knowledge: Further Essays in Interpretive Anthropology. New York: Basic Books.

Gentile, D. A. and W. Stone. 2005. "Violent Video Game Effects on Children and Adolescents. A Review of the Literature." Minerva Pediatr 57: 337-358.

Greitemeyer, Tobias and Dirk O. Mugge. 2014. "Video Games Do Affect Social Outcomes: A Meta-Analytic Review of the Effects of Violent and Prosocial Video Game Play." Personality and Social Psychology Bulletin 40: 578-589.

Greitemeyer, T., E. Traut-Mattausch, and S. Osswald. 2012. "How to Ameliorate Negative Effects of Violent Video Games on Cooperation: Play it Cooperatively in a Team." Computers in Human Behavior 28: 1465-1470.

Griffiths, M. D. 2000. "Video Game Violence and Aggression: Comments on 'Video Game Playing and its Relations with Aggressive and Prosocial Behavior' by O. Wiegmam and E.G.M. van Schie.” Br J Soc Psychol 39: 147-149.

Griffiths, M. 2008. "Videogame Addiction: Further Thoughts and Observations." International Journal of Mental Health and Addiction 6(2): 182-185.

Griffiths, M. D. and N. Hunt. 1995. "Computer Game Playing in Adolescence: Prevalence and Demographic Indicators.” Journal of Community \& Applied Social Psychology 5(3): 189193. 
Griffiths, M. D., M. N. Davies, and D. Chappell. 2003. "Breaking the Stereotype: The Case of Online Gaming." CyberPsychology and Behavior 6: 81-91.

Griffiths, M. D., M. N. Davies, and D. Chappell. 2004. "Online Computer Gaming: A Comparison of Adolescent and Adult Gamers." Journal of Adolescence 27(1): 87-96.

Grusser, S. M., R. Thalemann, and M. D. Griffiths. 2007. "Excessive Computer Game Playing: Evidence for Addiction and Aggression?" Cyberpsychology and Behavior 10(2): 290292.

Hand, M. and K. Moore. 2006. "Community, Identity, and Digital Games." Pp.166-182 in Understanding Digital Games, edited by J. Rutter and J. Bryce. London: Sage.

Harman, J. P., C. E. Hansen, M. E. Cochran, and C. R. Lindsey. 2005. "Liar, Liar: Internet Faking but not Frequency of use Affects Social Skills, Self-Esteem, Social Anxiety, and Aggression." CyberPsychology and Behavior 8: 1-6.

Hartmann, T. and C. Klimmt. 2006. "Gender and Computer Games: Exploring Females' Dislikes.” Journal of Computer-Mediated Communication 11(4): 910-931.

Hellstrom, Charlotta, Kent W. Nilsson, Jerzy Leppert, and Cecilia Aslund. 2012. "Influences of Motives to Play and Time Spent Gaming on the Negative Consequences of Adolescent Online Computer Gaming." Computers in Human Behavior 28: 1379-1387.

Holtz, P. and M. Appel. 2011. "Internet Use and Video Gaming Predict Problem Behavior in Early Adolescence." Journal of Adolescence 34(1): 49-58.

Hsiao, Cheng-Chieh, and Jyh-Shen Chiou. 2012. "The Effects of a Player's Network Centrality on Resource Accessibility, Game Enjoyment, and Continuance Intention: A Study on Online Gaming Communities." Electronic Commerce Research and Applications 11: 7584.

Hsu, C. L. and H. P. Lu. 2004. "Why do People Play On-line Games? An Extended TAM with Social Influences and Flow Experience." Information and Management 41(7): 853-868.

Hsu, C. L. and H. P. Lu. 2007. "Consumer Behavior in Online Game Communities: A Motivational Factor Perspective." Computers in Human Behavior 23(3): 1642-1659.

Hsu, S. H., M. H. Wen, and M. C. Wu. 2009. "Exploring User Experiences as Predictors of MMORPG Addiction." Computers \& Education 53(2): 990-999.

Hussain, Z. and M. Griffiths. 2009. "Excessive Use of Massively Multi-Player Online RolePlaying Games: A Pilot Study." International Journal of Mental health and Addiction 7(4): 563-571.

Huvila, I., K. Holmberg, S. Ek, and W. Widen-Wulff. 2010. "Social Capital in Second Life." Online Information Review 34: 295-316.

Iacono, C. S. and S. Weisband. 1997. "Developing Trust in Virtual Teams." Paper presented at the Hawaii International Conference on System Sciences, Hawaii. 
Id Software. 1993. Doom. Video Game. New York, NY: GT Interactive.

Infinity Ward. 2013. Call of Duty: Ghosts. Video Game. Santa Monica, CA: Activision.

Jennett, C., A. L. Cox, P. Cairns, S. Dhoparee, A. Epps, T. Tijs, and A. Wilson. 2008. "Measuring and Defining the Experience of Immersion in Games." International Journal of Human-Computer Studies 66: 641-661.

Karmali, L. 2014. "Destiny is the World's Best-Selling New Franchise Ever." IGN.com. Retrieved September 18, 2014 (http://www.ign.com/articles/2014/09/17/destiny-is-theworlds-best-selling-new-franchise-ever).

Katz, E., J. G. Blumler, and M. Gurevitch. 1974. "Utilization of Mass Communication by the Individual." In The Use of Mass Communications: Current Perspectives on Gratifications Research, edited by J. G. Blumler and E. Katz. Beverly Hills, CA: SAGE.

Kim, H. K., and K. E. Davis. 2009. "Towards a Comprehensive Theory of Problematic Internet Use: Evaluating the Role of Self-Esteem, Anxiety, Flow, and The Self-Rated Importance of internet Activities." Computers in Human Behavior 25: 490-500.

Kim, M. G. and J. Kim. 2010. "Cross-Validation of Reliability, Convergent, and Discriminant Validity for the Problematic Online Game Use Scale." Computers in Human Behavior 26(3): 389-398.

Kim, Eun Joo, Kee Namkoong, Taeyun Ku, and Se Joo Kim. 2008. "The Relationship Between Online Game Addiction and Aggression, Self-Control and Narcissistic Personality Traits." European Psychiatry 23: 212-218.

Ko, C. H., J. Y. Yen, C. C. Chen, S. H. Chen, and C. F. Yen. 2005. "Gender Differences and Related Factors Affecting Online Gaming Addiction Among Taiwanese Adolescents." The Journal of Nervous and Mental Disease 193(4): 273-277.

Kock, N. 2005. "Media Richness or Media Naturalness? The Evolution of our Biological Communication Apparatus and its Influence on our Behavior Toward E-Communication Tools." IEEE Transactions on professional Communication 48(2): 117-130.

Kolo, C. and T. Baur. 2004. "Living a Virtual Life: Social Dynamics of Online Gaming." International Journal of Computer Game Research 4(1).

Koo, D. K. 2009. "The Moderating Role of Locus of Control on the Links Between Experiential Motives and Intention to Play Online Games." Computers in Human Behavior 25(2): $466-474$.

Kowert, Rachel and Julian A. Oldmeadow. 2013. "(A)Social Reputation: Exploring the Relationship Between Online Video Game Involvement and Social Competence." Computers in Human Behavior 29: 1872-1878.

Lin, Chieh-Peng. 2011. "Assessing the Mediating Role of Online Social Capital Between Social Support and Instant Messaging Use." Electronic Commerce Research and Applications 10: 105-114. 
Lin, Yu-Ling and Hong-Wen Lin. 2011. "A Study on the Goal Value for Massively Multiplayer Online Role-Playing Games Players.” Computers in Human Behavior 27: 2153-2160.

Liu, M. and W. Peng. 2008 “A Cognitive Model for Understanding Online Gaming Addiction." Paper presented at the Annual Conference of the International Communication Association. Retrieved September 5, 2014 (http://citation.allacademic.com//meta/p_mla_apa_research_citation/2/3/4/4/2/pages 2344 23/p234423-2.php).

Liu, M. and W. Peng. 2009. "Cognitive and Psychological Predictors of the Negative Outcomes Associated with Playing MMOGs (Massively Multiplayer Online Games)." Computers in Human Behavior 25(6): 1306-1311.

Lo, S. K., C. C. Wang, and W. Fang. 2005. "Physical Interpersonal Relationships and Social Anxiety Among Online Game Players." CyberPsychology and Behavior 8(1): 15-20.

Sony Online Entertainment. 2003. Star Wars: Galaxies. Video Game. San Diego, CA: LucasArts.

McKenna, K. Y. A., A. S. Green, and M. E. J. Gleason. 2002. "Relationship Formation on the Internet: What's the Big Attraction?” Journal of Social Sciences 58(1): 9-31.

Microsoft. 2014. Microsoft by the Numbers. Retrieved September 5, 2014 (http://www.microsoft.com/en-us/news/bythenumbers/index.html).

MMOdata.net. 2012. Retrieved September 5, 2014 (http://users.telenet.be/mmodata/Charts/Subs1.png).

Morahan-Martin, J. and P. Schumacher. 2000. "Incidence and Correlates of Pathological Internet Use Among College Students." Computers in Human Behavior 16: 13-29.

Morahan-Martin, J. and P. Schumacher. 2003. "Loneliness and Social uses of the Internet." Computers in Human Behavior 19: 659-671.

Ng, B. D. and P. Wiemer-Hastings. 2005. "Addiction to the Internet and Online Gaming." CyberPsychology and Behavior 8: 110-113.

Nielsen. 2010. What Americans Do Online: Social Media and Games Dominate Activity. Retrieved September 5, 2014 (http://www.nielsen.com/us/en/insights/news/2010/whatamericans-do-online-social-media-and-games-dominate-activity.html).

Niemz, K., M. Griffiths, and P. Banyard. 2005. "Prevalence of Pathological Internet Use Among University Students and Correlations with Self-Esteem, the General Health Questionnaire (GHQ) and Disinhibition." CyberPsychology and Behavior 8: 562-570.

Noonan, R.J. 1998. "The Psychology of Sex: A Mirror From the Internet (Ed.), Psychology and the Internet: Intrapersonal, Interpersonal, and Transpersonal Implications. San Diego, CA: Academic Press. 
O’Brien, L. 2014. “Average Destiny Session is 3 Hours, 4 on Weekends.” IGN.com. Retrieved October 9, 2014 (http://www.ign.com/articles/2014/09/22/average-destiny-session-is-3hours-4-on-weekends).

Park, Seung-bae and Namho Chung. 2011. "Mediating Roles of Self-Presentation Desire in Online Game Community Commitment and Trust Behavior of Massive Multiplery Online Role-Playing Games." Computers in Human Behavior 27: 2372-2379.

Parsons, Talcott. 1951. The Social Systems. London: Routledge \& Kegan Paul Ltd. Retrieved September 6, 2014 (http://home.ku.edu.tr/ mbaker/CSHS503/TalcottParsonsSocialSystem.pdf).

Pena, J. and J. T. Hancock. 2006. “An Analysis of Socioemotional and Task Communication in Online Multi-Player Video Games." Communication Research 33(1): 92-109.

PlayStationLifeStyle.net. 2013. PSN Passes 110 Million Accounts, Sony Pictures Developing Exclusive "Original TV-Style Programming” for PSN, Timed Exclusives. Retrieved September 5, 2014 (http://www.playstationlifestyle.net/2013/07/03/psn-passes-110million-accounts-sony-pictures-developing-exclusive-original-tv-style-programming-forpsn-timed-exclusives/).

Pornsakulvanich, V. P. Haridakis, and A. M. Rubin. 2008. "The Influence of Dispositions and Internet Motivation on Online Communication Satisfaction and Relationship Closeness." Computers in Human Behavior 24(5): 2292-2310.

Puri, Kunal and Rudy Pugliese. 2012. "Sex, Lies, and Video Games: Moral Panics or Uses and Gratifications.” Bulletin of Science Technology \& Society 32: 345-352.

Putnam, R. D. 1993. Making Democracy Work: Civic Traditions in Modern Italy. Princeton, NJ: Princeton University Press.

Putnam, R. D. 2000. Bowling Alone: The Collapse and Revival of American Community. New York: Simon \& Schuster.

Shapira, N. A., T. D. Goldsmith, P. E. Keck Jr., U. M. Khosla, S. L. McElroy. 2000. "Psychiatric Features of Individuals with Problematic Internet Use.” Affect Disord 57: 267-272.

Shapira, N. A., M. C. Lessig, T. D. Goldsmith, S. T. Szabo, M. Lazoritz, and M. S. Gold. 2003. "Problematic Internet Use: Proposed Classification and Diagnostic Criteria." Depression and Anxiety 17: 207-216.

Sharif, L. and J. D. Sargent. 2006. "Association Between Television, Movie, and Video Game Exposure and School Performance." Pediatrics 118(4): 1061-1070.

Sheperd, R. M. and R. J. Edelmann. 2005. "Reasons for Internet Use and Social Anxiety." Personality and Individual Differences 39: 949-958.

Skorik, M. M. and G. C. E. Kwan. 2011. "Platforms for Mediated Sociability and Online Social Capital: The Role of Facebook and Massively Multiplayer Online Games." Asian Journal of Communication 21(5): 467-484. 
Smahel, D., A. Sevcikova, L. Blinka, and M. Vesela. 2009. “Abhangigkeit and Internet Appllikationen: Spiele, Kommunikation and Sex-Webseiten.” Pp. 235-260 in Gesundheit und Neue Medien, edited by B. U. Stetina and I. Kryspin-Exner. Vienna: Springer.

Small, Mario Luis. 2009. "How Many Cases Do I Need?: On Science and the Logic of Case Selection in Field-Based Research.” Ethnography 10(5). Retrieved September 6, 2014 (http://eth.sagepub.com/cgi/content/abstract/10/1/5).

Snodgrass, Jeffrey G., Michael G. Lacy, H.J. Francoi Dengah II, and Jesse Fagan. 2011. "Enhancing One Life Rather than Living Two: Playing MMOs with Offline Friends." Computers in Human Behavior 27: 1211-1222.

Song, I., R. LaRose, M. S. Eastin, and C. A. Lin. 2004. "Internet Gratifications and Internet Addiction: On the Uses and Abuses of New Media." CyberPsychology and Behavior 7: 384-389.

Spada, M. M., B. Langston, A. V. Nikcevic, and G. B. Moneta. 2008. "The Role of Metacognitions in problematic Internet Use." Computers in Human Behavior 24: 23252335.

Steinkuehler, C. A., and D. Williams. 2006. "Where Everybody Knows Your Name: Online Games as 'Third Places'.” Journal of Computer-Mediated Communication 11(4): 885909.

Stepanikova, I., N. H. Nie, and X. He. 2010. "Time on the Internet at Home, Loneliness, and Life Satisfction: Evidence from Panel Time-Diary Data." Computers in Human Behavior 26: 329-338.

Tarzawa, Y. and K. Okada. 2001. "Physical Signs Associated with Excessive Television-Game Playing and Sleep Deprivation.” Pediatrics International 43(6): 647-650.

Taylor, T. L. 2006. Play Between Worlds: Exploring Online Game Culture. Cambridge: MIT Press.

Thalemann, R. K. Wolfing, and S. M. Grusser. 2007. "Specific Cue Reactivity on Computer Game-Related Cues in Excessive Gamers.” Behavioral Neuroscience 121(3): 614-618.

Trepte, Sabine, Leonard Reinecke, and Keno Juechems. 2012. "The Social Side of Gaming: How Playing Online Computer Games Creates Online and Offline Social Support." Computers in Human Behavior 28: 832-839.

Turkle, S. 1995. Life on the Screen: Identity in the Age of the Internet. New York: Simon \& Schuster.

Van den Buck, J. 2004. "Television Viewing, Computer Game Playing, and Internet Use and Self-Reportedd Time to Bed and Time Out of Bed in Secondary-School Children." Sleep 27(1): 101-104.

Villani S. 1999. "Violence in the Media." J Am Acad Child Adolesc Psychiatry 38: 1208. 
Wallace, P.M. 1999. The Psychology of the Internet. New York: Cambridge University Press.

Walther, J.B. 1996. “Computer-Mediated Communication: Impersonal Interpersonal, and Hyperpersonal Interaction.” Communication Research 23: 3-43.

Weibull, L. 1985. "Structural Factors in Gratifications Research.” Pp. 123-147 in Media Gratifications Research: Current Perspectives, edited by K. E. Rosengren, L. A. Wenner, and P. Palmgreen. Beverly Hills, CA: SAGE.

Whang, L. S. and G. Chang. 2004. "Lifestyles of Virtual World Residents: Living in the On-Line Game 'Lineage'." CyberPsychology and Behavior 7: 592-600.

Williams, D. 2006. "Groups and Goblins: The Social and Civic Impact of an Online Game. Journal of Broadcasting \& Electronic Media 50(4): 651-670.

Williams, D., N. Ducheneaut, L. Xiong, N. Yee, and E. Nickell. 2006. "From Tree House to Barracks." Games and Culture 1(4): 338-361.

Wolvendale, J. 2006. "My Avatar, My Self: Virtual Harm and Attachment.” Pp. 305-310 in Cyberspace2005, edited by R. Polcak, M. Skop, and D. Smahel. Brno: Masaryk University.

Wu, Jen-Her, Shu-Ching Wang, and Ho-Huang Tsai. 2010. "Falling in Love With Online Games: The Uses and Gratifications Perspective." Computers in Human Behavior 26: 1862-1871.

Ybarra, M. L., C. Alexander, and K. J. Mitchell. 2005. "Depressive Symptomatology, Youth Internet Use, and Online Interactions: A National Survey. Journal of Adolescent Health 36: $9-18$

Yee, N. 2002. Befriending Ogres and Wood-Elves- Understanding Relationship Formation in MMORPGs. Nickyee.com. Retrieved September 5, 2014 (http://www.nickyee.com/hub/relationships/relationships.pdf).

Yee, N. 2006a. “The Labor of Fun.” Games and Culture 1(1): 68-71.

Yee N. 2006b. "Motivations for Play in Online Games.” CyberPsychology and Behavior 9(6): $772-775$

Yin, R. 2002. Case Study Research. Thousand Oaks, CA: SAGE.

Young, K. S. and R. C. Rogers. 1998. "The Relationship Between Depression and Internet Addiction." CyberPsychology and Behavior 1: 25-28.

Zhong, Zhi-Jin. 2011. "The Effects of Collective MMORPG (Massively Multiplayer Online Role-Playing Games) Play on Gamers' Online and Offline Social Capital." Computers in Human Behavior 27: 2352-2363. 